\title{
Human scleral elastic system: an immunoelectron microscopic study
}

\author{
George Evelyn Marshall
}

\begin{abstract}
An immunocytochemical study was conducted on elastic components in the sclera of seven aged human eyes. By conventional electron microscopy, elastic tissue consists of three distinct fibre types - elastic fibres, elaunin fibres, and oxytalan fibres. The distribution of six components associated with the elastic system (elastin, amyloid P component, laminin, fibronectin, gp 115, and vitronectin) were studied by immunogold transmission electron microscopy. The codistribution of amyloid $P$ component and laminin was further studied by double immunolabelling. Both elastic and elaunin fibres contained elastin. The microfibrillar sheaths of elastic fibres labelled for amyloid $P$ component, those of elaunin fibres for amyloid $P$ and laminin, and those of oxytalan fibres for laminin only. No labelling was observed for fibronectin, gp 115, and vitronectin. In terms of the proteins investigated, the biochemical profile of the three fibre types was not completely identical and was manifest as different affinities in the binding of serum amyloid $P$ component and an association with laminin.
\end{abstract}

(Br f Ophthalmol 1995; 79: 57-64)

The human eye possesses an elastic system within the trabecular meshwork, ${ }^{1-3}$ the choroid, ${ }^{14}$ the optic nerve head, ${ }^{15}$ and the sclera. ${ }^{167}$ Knowledge of the basic constituents of elastic tissue is essential for an understanding of normal function and many disease states. The principal components of elastic tissue are collagen, a fibrous protein that provides considerable tensile strength, and an elastic fibre system (reviewed by Cleary and Gibson $^{8}$ ), which gives the tissue stretchability. ${ }^{9}$ The elastic fibre system is composed of three types of fibres: elastic fibres, elaunin fibres, and oxytalan fibres. By conventional transmission electron microscopy, elastic fibres are seen to consist of two components: an amorphous electron dense core surrounded by a sheath of microfibrils. Oxytalan fibres are collections of typical microfibrils unassociated with amorphous material. Elaunin fibres are intermediate in size between oxytalan and elastic fibres and consist of bundles of typical microfibrils associated with small amounts of elastic type amorphous material.

By light microscopic examination of human sclera, using special stains, Alexander and Garner ${ }^{1}$ showed that all three fibre types of the elastic system occurred in the middle and inner layers of the posterior sclera, but only in the inner layer of the anterior sclera. Elaunin fibres extended further forward towards the limbus and oxytalan fibres were the most abundant of the three. ${ }^{1}$

The biochemical nature of elastic components has been studied by immunohistochemistry at the light microscopic level in the chick eye ${ }^{10}$ and in a number of non-ocular tissues. Elastic fibres in arteries, striated muscle, skin, and lung of the chick and rat have been shown to contain the protein elastin ${ }^{1011}$ and a number of glycoproteins have been localised to the microfibrillar component of the bovine elastic system, including fibrillin, ${ }^{12}$ microfibril associated glycoprotein (MAGP), ${ }^{13-16}$ and fibronectin. ${ }^{17} 18$ Vitronectin has been shown to be associated with elastic fibres of human skin ${ }^{19}$ and fibrillin with their microfibrillar component. ${ }^{20}$ The presence of fibrillin has also been demonstrated in microfibrils of human fibroblast cultures. ${ }^{21} 22$ Finally, amyloid P component has been associated with microfibrils in lens zonules and footpad of the mouse. ${ }^{23}$

No systematic immunocytochemical study has been conducted on the biochemical nature of the elastic fibre system in human sclera. An immunogold transmission electron microscopic study was therefore conducted on the localisation of elastin, amyloid P component, elastin associated glycoprotein (gp 115), fibronectin, vitronectin, and laminin to the elastic system of aged human sclera, using commercially available antibodies. Laminin

Table 1 Clinical details of surgical enucleations and postmortem eyes

\begin{tabular}{llll}
\hline Case No & Age & Sex & Indication for enucleation \\
\hline 1 & 49 & M & OT \\
2 & 68 & M & CBM \\
3 & 75 & M & PM (1 hour) \\
4 & 76 & F & OT \\
5 & 77 & F & CBM \\
6 & 88 & F & OT (3 hours) \\
7 & 89 & F & PM (3 h \\
\hline
\end{tabular}

$\mathrm{CBM}=$ ciliary body melanoma; $\mathrm{PM}=$ post mortem; $\mathrm{OT}=$ orbital tumour. Time interval between death and fixation is shown in parentheses. 
Table 2 Details of primary antibodies

\begin{tabular}{|c|c|c|c|c|c|}
\hline \multirow[b]{2}{*}{ Antigen } & \multirow[b]{2}{*}{ Type } & \multicolumn{2}{|c|}{ Dilution } & \multirow[b]{2}{*}{ Company } & \multirow[b]{2}{*}{ Specificity tests } \\
\hline & & $L R W$ & Cryo & & \\
\hline Amyloid P & Rabbit poly & $1: 200$ & $1: 1200$ & Dako, Denmark & $\begin{array}{l}\text { Crossed and rocket immunoelectrophoresis, single } \\
\text { radial immunodiffusion }\end{array}$ \\
\hline Elastin & Mouse mono & $1: 100$ & $1: 100$ & Sigma, UK & Immunoaffinity chromatography \\
\hline Fibronectin & Mouse mono & $1: 100$ & $1: 50$ & Sigma, UK & Immunoblot \\
\hline gp 115 & Mouse mono & $1: 150$ & $1: 800$ & Chemicon, USA & Immunoblotting, immunoprecipitation \\
\hline Laminin & Rabbit poly & $1: 40$ & $1: 40$ & Heyl, Germany & $\begin{array}{l}\text { ELISA, immunoblotting immunohistology } \\
\text { (fluorescence, APAAP) }\end{array}$ \\
\hline Vitronectin & Mouse mono & $1: 100$ & $1: 50$ & BCL, Germany & ELISA, Western blot \\
\hline
\end{tabular}

Antibody suppliers

BCL: Boehringer Mannheim House, Bell Lane, Lewes, East Sussex BN7 1LG, UK.

Chemicon: International Inc, 27515 Enterprise Circle West, Temecula, CA 92590, USA

Dako Ltd: 16 Manor Courtyard, Hughenden Avenue, High Wycombe HP13 5 RE, UK.

Heyl: Chemisch-pharmazeutische Fabrik GmbH \& Co KG, Goerzallee 253, D-1000 Berlin 37, Germany.

Sigma: Chemical Co Ltd, Fancy Road, Poole, Dorset BH1 7 7NH, UK.

LRW = London resin white.

ELISA = enzyme linked immunosorbent assay.

APAAP = alkaline phosphatase anti-alkaline phosphatase

was included in the present study, as previous work indicated that it is a constituent of the elastic system in the trabecular meshwork, ${ }^{24}$ and zonular (oxytalan) fibres of the lens. ${ }^{25}$ It was not possible to investigate the distribution of MAGP and fibrillin, as antibodies to these proteins are not commercially available.

\section{Materials and methods}

Scleral tissue was obtained from the macular region of seven eyes (Table 1): five surgically enucleated and two postmortem eyes. Indications for surgical enucleation are listed in Table 1; intraocular pressure before enucleation was normal. Autopsy specimens were ostensibly normal on macroscopic and microscopic examination of the fundus.

Surgically removed eyes were fixed immediately after enucleation in freshly prepared $4 \%$ paraformaldehyde (PFA) plus $0.5 \%$ glutaraldehyde in $0 \cdot 1 \mathrm{M}$ cacodylate buffer at $\mathrm{pH} 7.4$ with the addition of $3 \%$ sucrose. The two postmortem eyes were fixed within 3 hours of death in a similar manner to that of the surgical enucleations.

The macula and attached sclera was dissected out of enucleation specimens after 2 hours in fixative, subdivided into several pieces, and processed into London resin white (LR white) and for cryoultramicrotomy, as detailed in Marshall et al. ${ }^{26}$

IMMUNOCYTOCHEMISTRY - SINGLE LABELIING The immunocytochemical procedure is detailed in Marshall et al. ${ }^{27}$ Details of the primary antibodies, including specificity tests conducted by the suppliers, are given in Table 2. Rabbit primary antibodies (amyloid $P$ component, laminin, and vitronectin) were visualised by $10 \mathrm{~nm}$ goat anti-rabbit immunogold conjugate (British BioCell International, UK) and mouse primary antibodies (elastin, fibronectin, and elastin associated glycoprotein [gp 115]) by $10 \mathrm{~nm}$ goat anti-mouse immunogold (British BioCell International). The optimal working dilution of each primary antibody was experimentally determined. Higher dilutions were normally required for optimal labelling in ultrathin frozen sections (Table 2).
IMMUNOCYTOCHEMISTRY - DOUBLE LABELLING Double immunolabelling for laminin and amyloid $\mathrm{P}$ component was performed on LR white ultrathin sections by exposing one side of the grid to the immunolabelling procedure for amyloid $\mathrm{P}$ component and visualising with $10 \mathrm{~nm}$ goat anti-rabbit immunogold. This side was then briefly fixed in buffered $2 \%$ glutaraldehyde to prevent relocalisation of the antibodies to the opposite side. The entire immunoprocedure was performed on the opposite side of the grid with the laminin primary antibody which was visualised with $20 \mathrm{~nm}$ goat anti-rabbit immunogold. Laminin was visualised by $10 \mathrm{~nm}$ sized immunogold particles and amyloid $P$ with $20 \mathrm{~nm}$ immunogold particles in a separate double immunolabelling experiment. The use of opposite sides of the grid avoided the possibility that the second primary antibody could not bind to a specific site because of steric hindrance of the first antibody complex.

After single and double labelling procedures, the grids were stained with $1 \%$ aqueous uranyl acetate and viewed in a Jeol $1200 \mathrm{EX}$ transmission electron microscope.

\section{CONTROLS}

Two negative control procedures were used: omission of the primary antiserum and substitution of the primary antiserum with normal rabbit and mouse serum (Sigma) conducted at the same dilutions.

The criteria for positive localisation required the restriction of immunogold particles to discrete structures. Labelling was considered to be non-specific if a significant number of immunogold particles were present on internal negative controls. Internal negative controls were structures which should be devoid of immunogold particles. The most readily available internal negative controls present in scleral tissue were cell nuclei and cell cytoplasm.

\section{Results}

No obvious differences were noted in the morphological preservation of enucleated eyes versus postmortem eyes, nor could morphological features be related to age differences. 


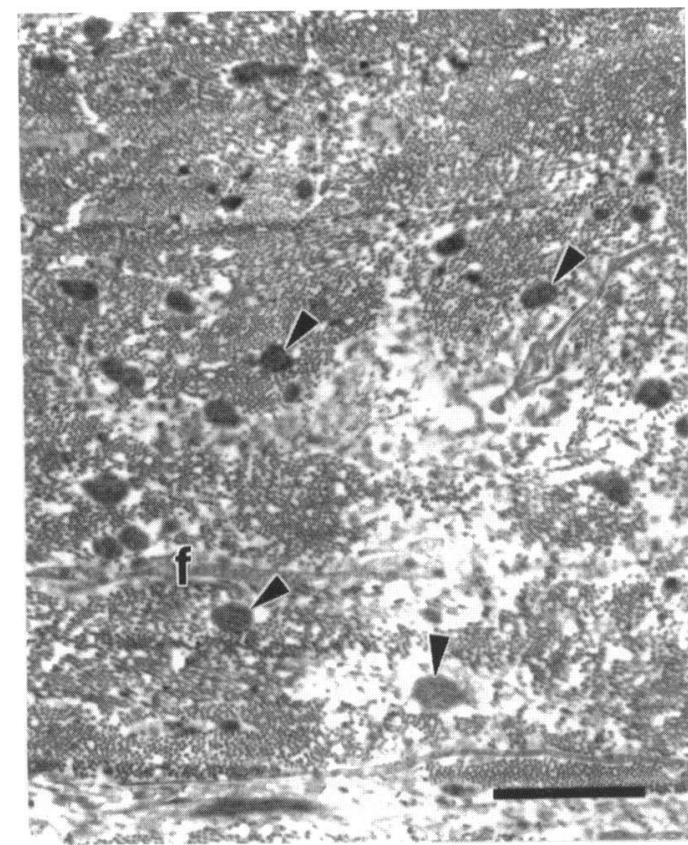

Figure 1 Transmission electron micrograph of inner sclera showing larger electron dense elastic fibres (arrowheads) between fine collagen fibrils. The elastic fibres are randomly scattered throughout the lamellae with several in close proximity to a scleral fibrocyte $(f)$. (LR white, bar=3 $\mu \mathrm{m}$.)

Elastic fibres appeared to be more abundant in the inner sclera bordering the choroid than in the outer sclera. Both elaunin and oxytalan fibres were evenly distributed throughout the thickness of the macular sclera. Differentiation between elastic and elaunin fibres was based on size only (elaunin fibres are smaller) as their structure was identical. All three fibre types were frequently associated with fibrocytes.

Heavy metal staining to enhance the electron density of elastic fibres was unnecessary for their identification: elastic fibres were easy to recognise within the collagen fibril bundles. The density of elastic fibres was greater adjacent to scleral fibrocytes (Fig 1). At high power the elastic fibres could be resolved into two components: an inner core and an outer 'fuzzy' sheath of microfibrils (Figs 2 and 3). The core in transverse section consisted of electron dense profiles embedded in a less electron dense homogeneous matrix. The width of these profiles was estimated to be about $20 \mathrm{~nm}$, using $10 \mathrm{~nm}$ gold particles as a scale marker. These electron dense profiles ran along the length of elastic fibres seen in longitudinal section (Figs 2b, 3b, 4a). The core was intimately surrounded by an electron dense granular sheath which in turn occasionally enclosed a number of collagen fibrils (Fig 5a). The sheath consisted of what sometimes appeared as granular material which was presumed to represent microfibrils but frequent examples of sheaths with an amorphous appearance were seen. The presence of tubular microfibrils within the sheath was rarely evident. Oxytalan fibres (Fig 4a, b) were differentiated from elastic fibres on the basis of their lacking an electron dense core and their fibrillar-like profiles with a hint of their tubular nature being seen when the fibres were cut in transverse section. Oxytalan fibres frequently occurred in the vicinity of the scleral fibroblasts, sometimes in close apposition to their
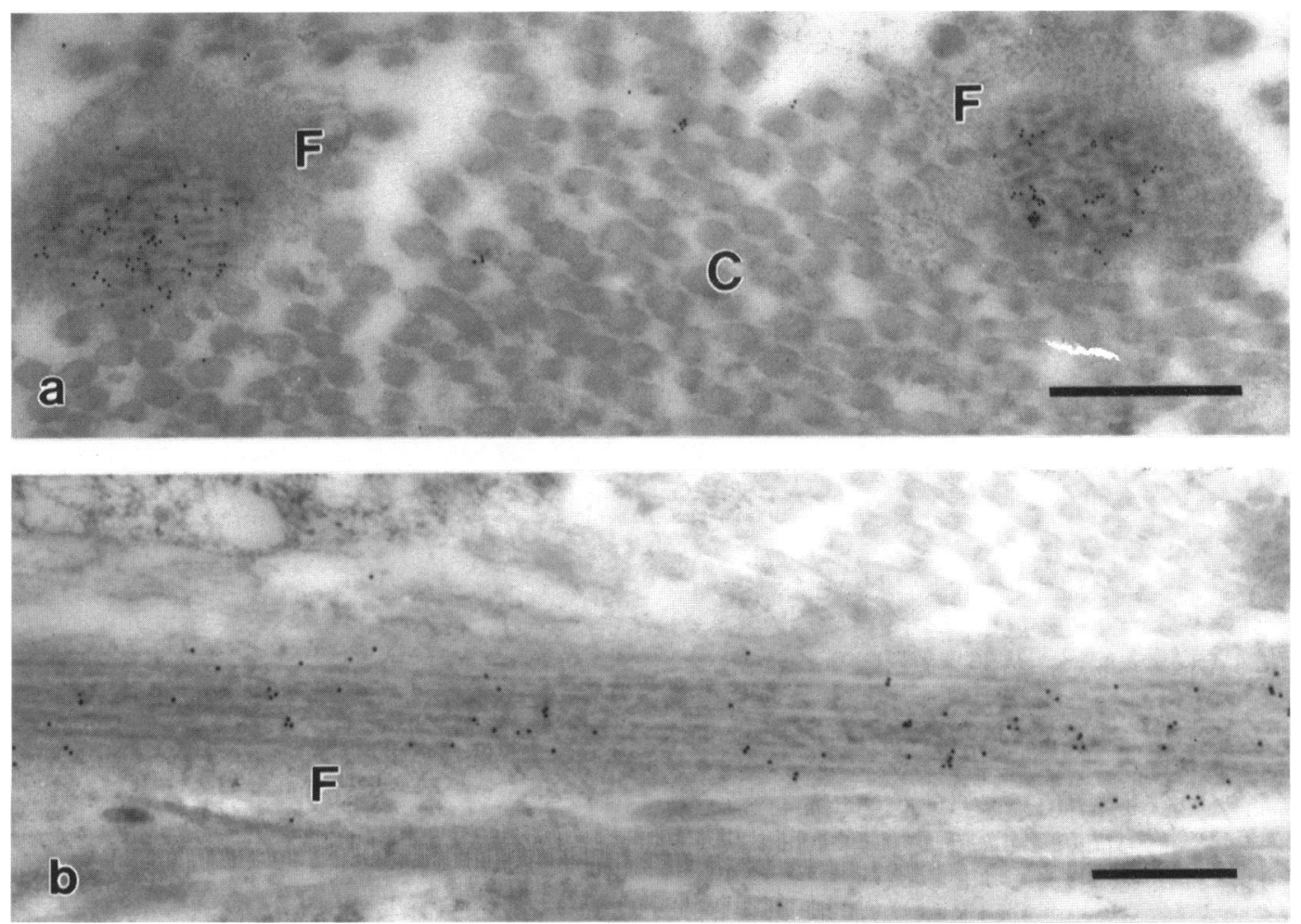

Figure 2 Scleral elastic fibres labelled with elastin antibodies (10 $\mathrm{nm}$ immunogold) (a) Transverse section. Labelling is restricted to the electron dense core with immunogold particles occurring over the border between the more electron dense profiles and the less electron dense amorphous matrix of the core. The core is surrounded by an electron dense compact granular material embedded in an electron dense matrix. Labelling for elastin is absent from this 'fuzzy' sheath ( $F)$. Immunogold particles over collagen fibrils $(C)$ are regarded as non-specific. (LR white, bar $=0.5 \mu m$.) (b) Longitudinal section of elastic fibre with $10 \mathrm{~nm}$ immunogold labelling for elastin occurring over electron dense profiles within the core of the elastic fibre. The 'fuzzy' sheath $(F)$ is free of label. (LR white, bar =0.5 $\mu \mathrm{m}$.) 

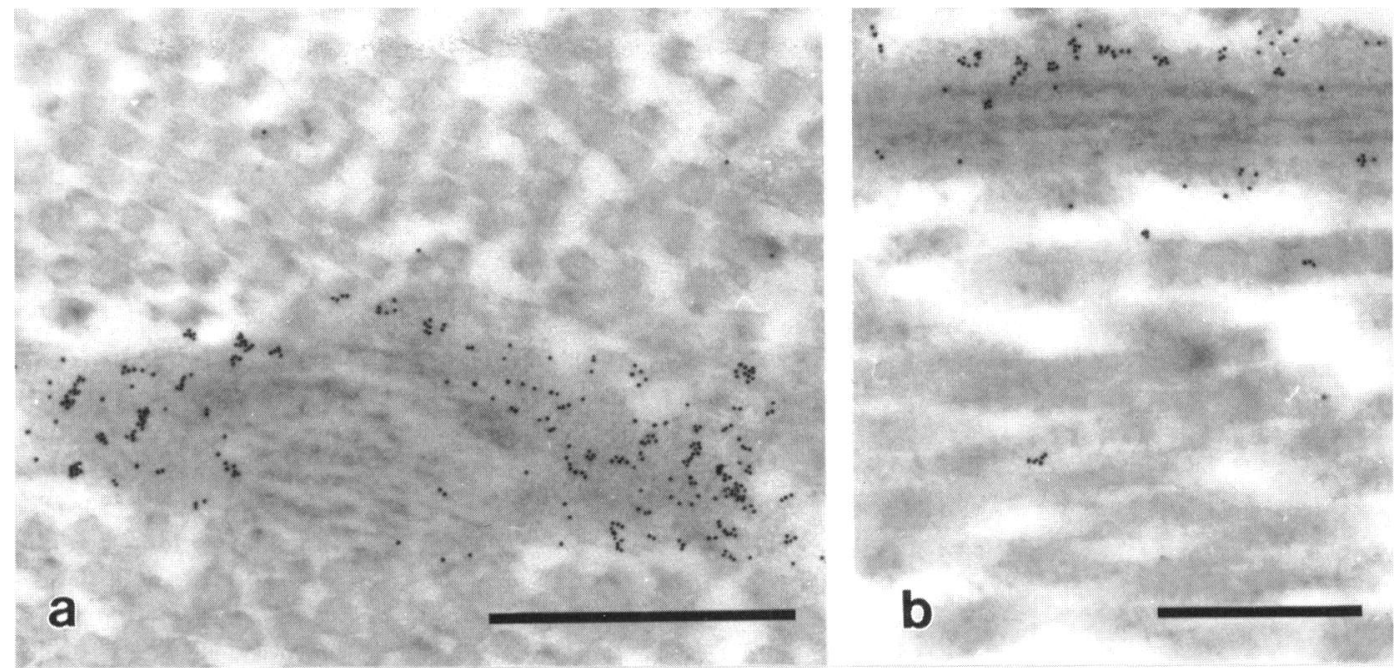

Figure 3 Amyloid P component labelling of elastic fibres. (a) Labelling is localised to the electron dense granular sheath surrounding the amorphous elastic core. The tubular nature of microfibrils within this sheath is not evident. Immunogold particles are absent from electron dense profiles within the core. (LR white, bar $=0.5 \mu \mathrm{m}$.) (b) Longitudinal section of elastic fibre with $10 \mathrm{~nm}$ immunogold labelling for amyloid $P$ component over its sheath of microfibrils. Note absence of immunogold particles from electron dense profiles within the elastic core. (LR white, bar $=0.5 \mu \mathrm{m}$.)

plasma membranes. Elaunin fibres (Fig 5c) were smaller than elastic fibres, but shared a similar structure.

\section{IMMUNOCYTOCHEMISTRY}

Both LR white and ultrathin frozen sections (cryoultramicrotomy) exhibited the same degree and distribution of labelling for all of
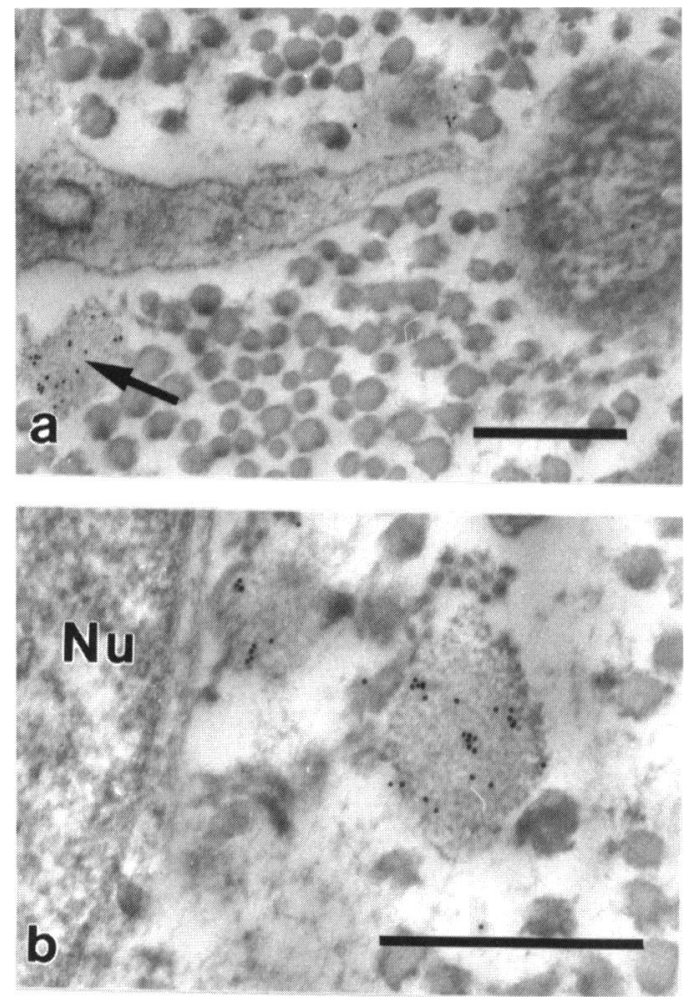

Figure 4 Laminin labelling of oxytalan fibres.

(a) Laminin localised to an oxytalan fibre at the left hand side of the micrograph above which lies a fibrocyte process.

Both the elastic core and microfibrillar sheath of the elastic fibre on the right hand side of the micrograph are devoid of label. (LR white, bar $=0.5 \mu \mathrm{m}$.) (b) Higher power of an oxytalan fibre labelled with laminin antibodies. The tubular nature of the microfibrils can be discerned. Note absence of labelling from nucleus (Nu) of adjacent scleral fibrocyte. (LR white, bar $=0.5 \mu \mathrm{m}$.) the components studied. However, significantly more non-specific labelling was present in ultrathin frozen sections and this was coupled with less effective tissue preservation. Specific labelling was observed for elastin, amyloid $\mathrm{P}$ component, and laminin. No specific labelling was observed for fibronectin, elastin associated glycoprotein (gp 115), or vitronectin with either tissue preparation technique.

\section{Elastin}

Elastin antibodies labelled the cores of elastic fibres (Fig 2). More specifically, labelling tended to occur at the edge of the electron dense profiles: immunogold particles rarely lay directly on top of the profiles or directly on top of the less electron dense homogeneous matrix and were not associated with the 'fuzzy' sheath. Labelling of the dense core of elaunin fibres was sparse and was completely absent from oxytalan fibres. Occasional gold particles noted over collagen fibrils were considered non-specific. Both cellular profiles and nuclei were free of label.

\section{Amyloid P component}

Antibodies against amyloid $\mathrm{P}$ component labelled the 'fuzzy' sheath of elastic fibres cut in both transverse and longitudinal sections (Fig 3). The elastic fibre core was generally free of label. Labelling for amyloid $P$ was also present over the 'fuzzy' sheath of elaunin fibres, but absent from the less electron dense core. Amyloid P component was also localised to extracellular matrix structures that lacked both an electron dense core and a fibrillar-like profile which were thought to be the 'fuzzy' sheath of either elastic or elaunin fibres (see above). Oxytalan fibres were also labelled, but the prevalence of immunogold particles was significantly less than that over the 'fuzzy' sheath of elastic and elaunin fibres. 

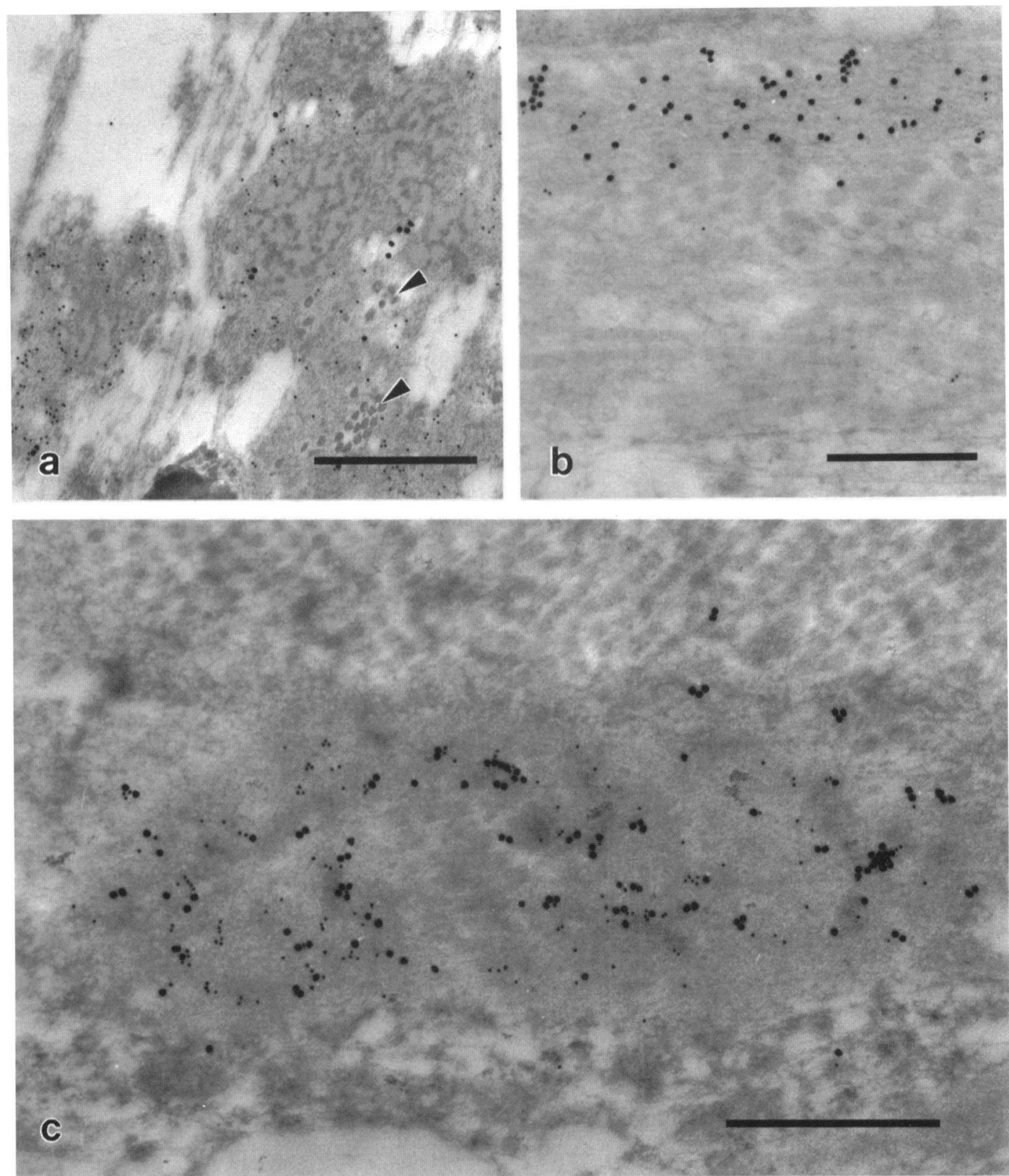

Figure 5 Double immunolabelling with amyloid P component ( $10 \mathrm{~nm}$ gold particles) and laminin ( $20 \mathrm{~nm}$ gold particles). (a) Labelling for amyloid $P$ component (10 $\mathrm{nm}$ particles) is present over the microfibrillar sheath of elastic fibres. Labelling for laminin (20 nm sized particles) is sparse and probably non-specific. Collagen fibrils (arrowheads) are present within the sheaths of microfibrils. (LR white, bar $=0.5 \mu \mathrm{m}$.) (b) A fibrillar-like oxytalan fibre cut in longitudinal section is almost exclusively labelled with anti-laminin antibodies $(20 \mathrm{~nm}$ particles). Little labelling for amyloid P component $(10 \mathrm{~nm}$ particles) is evident. (LR white, bar $=0.5 \mu \mathrm{m}$.) (c) The elastic core of this elaunin fibre does not exhibit typical differences in electron density. The lack of homogeneity is indicated by immunogold labelling: several small regions are devoid of label, whereas other areas label with amyloid P component and laminin and exhibit a uniform co-distribution of the two antigens. (LR white, bar $=0.5 \mu \mathrm{m}$.)

\section{Laminin}

Immunogold labelling with laminin antibodies was restricted to what was classed as oxytalan fibres (Fig 4), being largely absent from both the core and 'fuzzy' sheath of elastic fibres (Fig 4). Some labelling was also present over the 'fuzzy' sheath of elaunin fibres. As the single immunolabelling procedure could not clearly demonstrate if there was a lack of codistribution of amyloid $P$ component and laminin, a double immunolabelling procedure was also performed. Double immunolabelling confirmed the lack of co-distribution of amyloid $\mathbf{P}$ component and laminin in the 'fuzzy' sheath of elastic fibres (Fig 5a) and in the fibrillar-like oxytalan fibres (Fig 5 b).

The most striking feature of this study was the co-distribution of amyloid $\mathrm{P}$ component and laminin in elaunin fibres (Fig 5c). This labelling was specifically located in distinct regions of the elaunin matrix and the co-distribution appeared to be uniform (Fig 5c).

\section{CONTROLS}

Both the $10 \mathrm{~nm}$ and $20 \mathrm{~nm}$ immunogold negative controls (omission of primary antibody) were almost completely free of label. Nonspecific labelling with normal rabbit serum negative controls at 1:200 (amyloid P component negative control) (Fig 6) and 1:100 (elastin negative control) was minimal: nonspecific labelling was present at 1:30 (laminin negative control), particularly with the use of $20 \mathrm{~nm}$ goat anti-rabbit immunogold (Fig 6). 


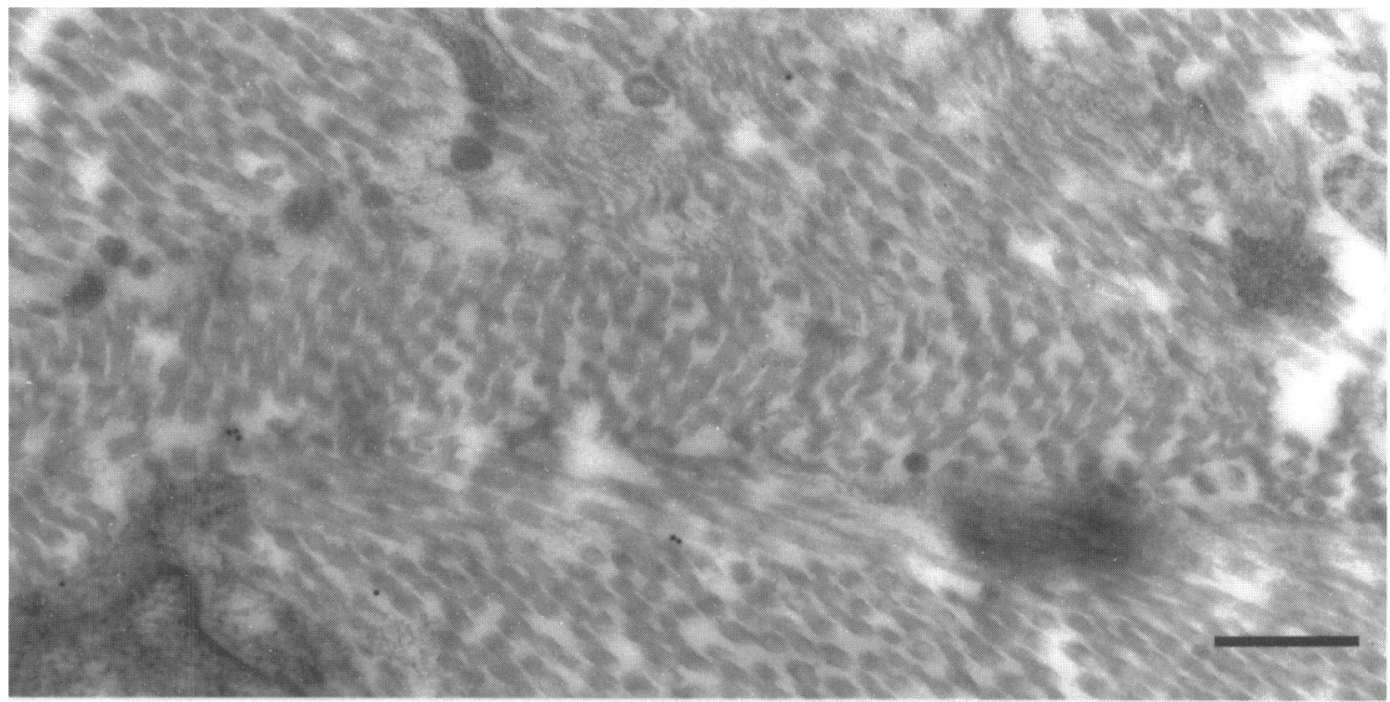

Figure 6 Normal rabbit serum (NRS) negative control for double labelling experiment. One side of the LR white grid was incubated with a 1:200 dilution of NRS followed by $10 \mathrm{~nm}$ goat anti-rabbit immunogold, and the other with a 1:30 dilution of NRS followed by $20 \mathrm{~nm}$ sized immunogold. Smaller sized immunogold particles are almost completely absent, but a number of the larger $20 \mathrm{~nm}$ immunogold particles are present. (LR white, bar $=0.5 \mu \mathrm{m}$.)

\section{Discussion}

The presence of all three fibre types (elastic, elaunin, and oxytalan fibres) of the elastic system in aged human macular sclera was confirmed, as was the absence of elastic fibres from the outer portion of the macular sclera. ${ }^{1}$ The elastic, elaunin, and oxytalan system of fibres are a feature of tissues subject to two or multidirectional stretching. ${ }^{28}$ The paucity of elastic fibres from the outer sclera may reflect biomechanical function. Presumably a greater percentage of collagen is required in the outer sclera to resist tension exerted by the short and rapid focal contraction of one or more of the six extraocular muscles. Elastication of this outer layer would be positively disadvantageous. It is also envisaged that the principal function of the scleral elastic system is to act as a buffer of resistance to intraocular pressure.

Employing two preparation techniques (LR white embedding and cryoultramicrotomy) in immunolabelling the scleral elastic system, served to strengthen the validity of the results. The same pattern of distribution for elastin, amyloid $\mathrm{P}$ component, and laminin was obtained with both tissue preparation techniques. No immunolabelling for fibronectin, gp 115 , and vitronectin was obtained with either technique. LR white embedding was the technique of choice, as cryoultramicrotomy was found to be more technically demanding and less effective in preserving fine structure.

The present study is the first to localise elastin to electron dense profiles in the amorphous cores of elastic fibres (Figs 2-3) and to the amorphous cores of elaunin fibres in the human sclera. The advent of immunogold electron microscopy has permitted the localisation of elastin antibodies to the amorphous core of elastic and elaunin fibres in a number of other tissues. ${ }^{1629}$ Previously, the association of elastin with the core of elastic fibres was deduced from enzyme digest experiments: the core was resistant to digestion by general proteases but was susceptible to elastases. ${ }^{8}$ Ultrastructural identification of elastin also relied on its affinity for heavy metal ions.
Newly formed elastin stains intensely with phosphotungstate, and mature elastin is darkened only after prolonged osmification, whereas the microfibrillar component is only heavily stained with uranyl acetate and lead citrate. ${ }^{30}$

In this study counterstaining of the core with heavy metals was not necessary in either LR white or ultrathin frozen sections to identify components of the elastic system and was avoided lest it obscure immunogold labelling for elastin. Staining with uranyl acetate alone was adequate in the visualisation of fine structural details in elastic fibres. Electron dense profiles were present within the amorphous elastic core: these may represent trapped microfibrils whose increased diameter from $12 \mathrm{~nm}$ to $20 \mathrm{~nm}$ is an aging feature of human elastic fibres. ${ }^{6}$ Close scrutiny of the immunogold particle labelling for elastin revealed a tendency to lie round the edge of the profiles within the core (Fig 2a). This suggests that the antibody binds preferentially to the epitopes which occur at this interface.

Although it was known that the immunoreactivity of elastin is unaffected by routine processing for conventional electron microscopy, ${ }^{31}$ previous experience in this laboratory indicated that the degree of immunoreactivity of other extracellular matrix components is dependent on fixation. Absence of labelling in the present study for elastin associated glycoprotein (gp 115), fibronectin, and vitronectin may be due to loss of immunoreactivity by overfixation. That collagen types I to VI were successfully localised on the same scleral tissue samples used here ${ }^{32}$ reflects a fundamental problem of immunocytochemistry: the variation in immunoreactivity of target proteins to fixation.

Absence of labelling in the present study for fibronectin may again be due to overfixation as its positive control (zonular [oxytalan] fibres of the lens) ${ }^{18}$ was unlabelled. Elastin associated glycoprotein (gp 115) and vitronectin have not been localised in human ocular tissues. The use of internal positive controls (areas within 
the same tissue block in which the antigen is known to occur) or other ocular positive controls was therefore not possible. No substitution was made with non-ocular positive controls for these two antibodies (tissue in which the antigens are known to be present and which has been processed in an identical manner). Elastin associated glycoprotein (gp 115) antibodies failed to label any of the scleral components in the present study. Absence of labelling is most probably due to overfixation as previous studies documenting the distribution of gp 115 have been performed on unfixed cryosections (light microscopic immunohistochemistry) where it exhibited co-distribution with tropoelastin in 2 day old chick liver, heart, skin, large vessels, striated muscle, and lymphoid organs. ${ }^{1033} 34$ (It is to be noted that the term gp 115 is also used for a totally unrelated sialoglycoprotein. ${ }^{35} 36$ )

The most striking labelling obtained in the present study was that for amyloid P component. Immunogold labelling of the sheaths that envelop the elastic cores was intense, both in elastic and elaunin fibres (Figs 4-5). Human serum amyloid $\mathrm{P}$ component (SAP) binds to all forms of amyloid fibril and is universally present in amyloid deposits, including the cerebral amyloid of Alzheimer's disease. ${ }^{37}$ SAP is a normal tissue matrix constituent associated with elastic fibres ${ }^{38} 39$ and microfibrils in the human skin and elastic microfibrils in the mouse zonule. ${ }^{23}$ It may protect elastic microfibrils from inappropriate degradation: protection could result simply from coating by SAP, which is completely unaltered with respect to its normal circulating form and which would therefore not be expected to trigger macrophage activation or phagocytosis. ${ }^{40}$

Inoue et $a l^{23}$ have concluded that microfibrillar tubules consist of a column of amyloid $P$ units. However, their findings have been disputed by other workers ${ }^{15} 16$ who suggest that the association of amyloid $\mathrm{P}$ component with microfibrils is due to an absorption of serum amyloid $P$ with increasing age.

The phenomenon 'fuzzy' sheath, used here to indicate the absence of microfibrillar detail in the sheath of elastic and elaunin fibres, may be caused by microfibrillar absorption of serum glycoproteins such as amyloid P component. The loss of microfibrillar detail (and presumably serum absorption) increases with age. In a conventional electron microscope study of the aging human sclera, Kanai and Kaufman $^{6}$ found that the tubular profile of microfibrils was apparent in scleral tissue of $2-3$ year olds, less obvious in a 16 and 22 year old (as microfibrils were more compact and possessed a slightly denser background) and completely absent in an 80 year old, in which differentiation between microfibrils and the surrounding ground substance was difficult. ${ }^{6}$ In the present study, a high density of the surrounding ground substance was associated with intense immunolabelling for amyloid $\mathbf{P}$ component. It is therefore proposed that the increased density of the surrounding ground substance is due to absorption of serum proteins and not to the degeneration of microfibrils suggested by Kanai and Kaufman. ${ }^{6}$ Further evidence for the above proposal is here derived from the absence of amyloid $\mathbf{P}$ labelling over (oxytalan) fibres which did not have an increased density of the surrounding ground substance. Absence of amyloid $P$ labelling is not likely to reflect recent synthesis of these oxytalan fibres, but more probably a selective binding of amyloid $\mathrm{P}$ component to elastic and elaunin fibre microfibrils. The latter possibility would suggest that elastic and elaunin microfibrils are not altogether identical to oxytalan microfibrils.

The lack of microfibril homogeneity is also reflected by immunolabelling for laminin: laminin antibodies labelled the microfibrils of oxytalan and elaunin fibres but not those of elastic fibres. The laminin antibody used in this laboratory labelled microfibrils in two other ocular tissues; the trabecular meshwork ${ }^{24}$ and zonular (oxytalan) fibres of the lens. ${ }^{25}$

In glaucoma, elastic fibres exhibit damage by losing their straight profiles and becoming curled like sine waves. ${ }^{7}$ This is thought to represent a disinsertion of the elastic fibres from surrounding fibrillar collagen, permitting their recoil to a point of relaxation. ${ }^{7}$ An obvious fundamental question is the nature of this insertion. As collagen fibrils were occasionally seen within the microfibrillar sheath (see Fig 5a) it is possible that the microfibrils are directly connected with the collagen fibrils. Since the present study indicates an association of laminin with elaunin and oxytalan fibres it is suggested that laminin may bind their microfibrils to collagen fibrils as it has been shown to have binding sites for several extracellular matrix components including collagen. ${ }^{41}$

I would like to express my indebtedness to Mrs Sophia Cameron for technical assistance and to Professor W R Lee for comments on the manuscript. This work was supported by the Sir Jules Thorn Charitable Trust.

1 Alexander RA, Garner A. Elastic and precursor fibres in the normal human eye. Exp Eye Res 1983; 36: 305-15.

2 Hirano K, Kobayashi M, Kobayashi K, Hoshino T, Awaya $\mathrm{S}$. Age-related changes of microfibrils in the cornea and trabecular meshwork of the human eye. $\mathcal{F p}_{\mathrm{f}} \mathcal{f}$ Ophthalmol 1991; 35: 166-74.

3 Lutjen-Drecoll E, Futa R, Rohen JW. Ultrahistochemical studies on tangential sections of the trabecular meshwork in normal and glaucomatous eyes. Invest Ophthalmol Vis Sci 1981; 21: 563-73.

4 Essner E, Gordon SR. Demonstration of microfibrils in Bruch's membrane of the eye. Tissue Cell 1984; 16: 779-88.

5 Hernandez MR. Ultrastructural immunocytochemical analysis of elastin in the human lamina cribrosa changes in elastic fibers in primary open-angle glaucoma. Inves Ophthalmol Vis Sci 1992; 33: 2891-903.

6 Kanai A, Kaufman HE. Electron microscopic studies of the elastic fiber in human sclera. Invest Ophthalmol 1972; 11: 816-21.

7 Quigley HA, Dorman-Pease ME, Brown AE. Quantitative study of collagen and elastin of the optic nerve head and Curr Eye Res 1991; 10: 877-88.

8 Cleary EG, Gibson MA. Elastin-associated microfibrils and microfibrillar proteins. Int Rev Connect Tissue Res 1983; 10: 97-209.

9 Ross R, Bornstein P. Elastic fibers in the body. Sci Am 1971; 224: 44-52.

10 Colombatti A, Poletti A, Bressan GM, Carbone A, Volpi D. Widespread codistribution of glycoprotein gp 115 and elastin in chick eye and other tissues. Coll Rel Res 1987; 7 259-75

11 Farquharson C, Robins SP. The distribution of elastin in developing and adult rat organs using immunocytochemical techniques. $\mathcal{F}$ Anat 1989; 165: 225-36. 
12 Shuttleworth CA, Berry L, Kielty CM. Microfibrillar components in dental pulp: presence of both type VI collagen and fibrillin containing microfibrils. Arch Oral Biol 1992; 37: $1079-84$.

13 Cleary EG, Gibson MA, Kumaratilake JS, Fanning JC. The microfibrillar component of elastic fibres. In: Tamburro AM, Davidson JM, eds. Elastin, chemical and biological aspects. Italy: Congedo Editore, 1990: 189-204.

14 Gibson MA, Hughes JL, Fanning JC, Cleary EG. The major antigen of elastin-associated microfibrils in a 31-kDa glycoprotein. 7 Biol Chem 1986; 261: 11429-36.

15 Gibson MA, Kumaratilake JS, Cleary EG. The protein components of the 12-nanometer microfibrils of elastic and nonelastic tissues. $\mathcal{F}$ Biol Chem 1989; 264: 4590-8.

16 Kumaratilake JS, Gibson MA, Fanning JC, Cleary EG. The tissue distribution of microfibrils reacting with a monospecific antibody to MAGP, the major glycoprotein antigen of elastin-associated microfibrils. Eur $¥$ Cell Biol 1989; 50: 117-27.

17 Schwartz E, Goldfischer S, Coltoff-Schiller B, Blumenfeld OO. Extracellular matrix microfibrils are composed of core proteins coated with fibronectin. $\mathcal{F}$ Histochem Cytochem 1985; 33: 268-74.

18 Goldfischer S, Coltoff-Schiller B, Goldfischer $M$ Microfibrils, elastic anchoring components of the extracellular matrix, are associated with fibronectin in the zonule of Zinn and aorta. Tissue Cell 1985; 17: 441-50.

19 Dahlback K, Lofberg H, Dahlback B. Localization of vitronectin (S-protein of complement) in normal human vitronectin (S-protein of complement) in normal h
skin. Acta Derm Venereol (Stockh) 1986; 66: 461-7.

20 Maddox BK, Sakai LY, Keene DR, Glanville RW. Connective tissue microfibrils: isolation and characterization of three large pepsin-resistant domains of fibrillin. f Biol Chem 1989; 264: 21381-5.

21 Fleischmajer R, Contard P, Schwartz E, MacDonald ED, Jacobs L, Sakai LY. Elastin-associated microfibrils $(10 \mathrm{~nm})$ in a three-dimensional fibroblast culture. $\mathcal{F}$ Invest Dermatol 1991; 97: 638-43.

22 Sakai LY, Keene DR, Engvall E. Fibrillin, a new 350-kD glycoprotein is a component of extracellular microfibrils. F Cell Biol 1986; 103: 2499-509.

23 Inoue S, Leblond CP, Grant DS, Rico P. The microfibrils of connective tissue; II immunohistochemical detection of the amyloid $\mathrm{P}$ component. Am $\mathcal{F}$ Anat 1986; 176: 139-52.

24 Marshall GE, Konstas AG, Lee WR. Immunogold localisation of type IV collagen and laminin in the aging human outflow system. Exp Eye Res 1990; 51: 691-9.

25 Marshall GE, Konstas AGP, Bechrakis NE, Lee WR. An immunoelectron microscope study of the aged human lens capsule. Exp Eye Res 1992; 54: 393-401.

26 Marshall GE, Konstas AGP, Lee.WR. Immunogold ultrastructural localization of collagens in the aged human outflow system. Ophthalmology 1991; 98: 692-700.
27 Marshall GE, Konstas AGP, Abraham S, Lee WR. Extracellular matrix in aged human ciliary body: an immunoelectron microscope study. Invest Ophthalmol Vis Sci 1992; 33: 2546-60.

28 Gawlik Z. Morphological and morphochemical properties of the elastic system in the motor organ of man. Folia Histochem Cytochem 1965; 3: 233-51.

29 Gordini DD, Castellani I, Barbolini U, Volpin D, Bressan GM. The organization of elastin in the chick eye. In: Tamburro AM, Davidson JM, eds. Elastin, chemical and biological aspects. Italy: Congedo Editore, 1990: 179-88.

30 Gosline JM, Rosenbloom J. Elastin. In: Piez KA, Reddi AH, eds. Extracellular matrix biochemistry. New York: Elsevier, 1984: 191-227.

31 White JF, Hughes JL, Kumaratilake JS, Fanning JC, Gibson MA, Krishnan R, et al. Post-embedding methods for immunolocalization of elastin and related compo

32 Marshall GE, Konstas AGP, Lee WR. Collagens in the aged human macular sclera. Curr Eye Res 1993; 12: 143-53. 33 Colombatti A, Bressan GM, Castellani I, Volpin D. Glycoprotein 115, a glycoprotein isolated from chick blood vessels, is widely distributed in connective tissue. fCell Biol 1985; 100: 18-26.

34 Colombatti A, Poletti A, Carbone A, Volpin D, Bressan GM. Extracellular matrix of lymphoid tissues in the chick. 7 Histochem Cytochem 1989; 37: 757-63.

35 Spring FA, Anstee DJ. Lectin-binding components of normal granulocytes and leukaemic myeloid cells. Biochem $\mathcal{F}$ 1983; 213: 661-70

36 Bressan GM, Castellani I, Colombatti A, Volpin D. Isolation and characterization of a 115,00-dalton matrixassociated glycoprotein from chick aorta. 7 Biol Chem 1983; 258: 13262-7.

37 Coria F, Castano E, Prelli F, Larrondo-Lillo M, van Duinen S, Shelanski ML, et al. Isolation and characterization of amyloid P component from Alzheimer's disease and other types of cerebral amyloidosis. Lab Invest 1988; 58: 454-8.

38 Breathnach SM, Melrose SM, Bhogal B, deBeer FC, Black MM, Pepys MB. Immunohistochemical studies of amyloid $\mathrm{P}$ component distribution in normal human skin. f Invest Derm 1983; 80: 86-90.

39 Pepys MB, Baltz ML, deBeer FC, Dyck RF, Holford S, Breathnach SM, et al. Biology of serum amyloid P component. Ann NY Acad Sci 1982; 389: 286-98.

40 Emsley J, White HE, O'Hara BP, Oliva G, Srinivasan N, Tickle IJ, et al. Structure of pentameric human serum amyloid P component. Nature 1994; 367: 338-45.

41 Ayad S, Boot-Handford RP, Humphreys MJ, Kadler KE, Shuttleworth CA. The extracellular matrix facts book. London: Academic Press, 1994: 111-9. 